\title{
Marginal peri-implant bone loss associated with two implant macrostructures: a prospective symmetrical split mouth study
}

IMPLANT THERAPY

OUTCOMES, PERI-IMPLANT BIOLOGY ASPECTS

\section{Abstract}

Background: The influence of the implant collar design on marginal peri-implant bone loss (MBL) is still controversial.

Aim: To compare MBL in 2 implants with a conical or straight collar, provided with identical surfaces, prosthetic connections, diameters and lengths.

Materials and Methods: Ten patients with single tooth symmetric posterior edentulous spaces, received a straight collar implant in one site and a conical collar implant in the symmetric contralateral one. Patients were followed-up for 36 months to evaluate: a) MBL; b) implant survival and success rates; c) peri-implant probing depth (PD) and bleeding on probing (BOP).

Results: No significant differences were observed among the two groups for all outcome variables.

Conclusions: Large diameter implants with a straight or conical implant collar design seem to perform evenly in the rehabilitation of single tooth posterior edentulous spaces.

\section{Background and Aim}

Stable peri-implant bone levels are unanimously considered a fundamental premise to achieve success in implant dentistry. Heterogenous results were published with respect to the influence of a conical versus straight implant collars design on marginal peri-implant bone loss (MBL). The first observations on conical implants with a machined neck reported higher values of MBL compared to straight implant fixtures. However, further investigations reported controversial outcomes, supporting no difference in MBL between conical and straight implant collars on one hand, and significant differences on the other.

The purpose of this randomized split-mouth clinical trial was to assess whether two implant fixtures with identical surfaces, prosthetic connections, coronal diameters and lengths, exhibit any significant difference in: a. MBL; b. implant success and survival rates; c. periimplant probing depth (PD) and bleeding on probing (BOP), after a 3 year follow-up period.

\section{Methods and Materials}

Ten patients presenting with single tooth symmetric posterior edentulous spaces, received a straight collar implant in one site (OsseoSpeed TX 5.0 S Astra Tech Implant System), and a conical collar implant in the symmetric contralateral one (OsseoSpeed TX 5.0, Astra Tech Implant System). All edentulous sites did not require bone regeneration in order to place $5 \mathrm{~mm}$ implants with a minimum length of $9 \mathrm{~mm}$, as the inclusion criteria required a minimum residual bone height of $12 \mathrm{~mm}$ and a minimum residual bone width of $7 \mathrm{~mm}$ per site. All patients received implants with matching lengths in the two symmetric sites. Patients were followed-up for 36 months to evaluate: a) MBL; b) implant survival and success rates according to Albrektsson et al. criteria (1986); c) peri-implant probing depth (PD) and bleeding on probing (BOP).
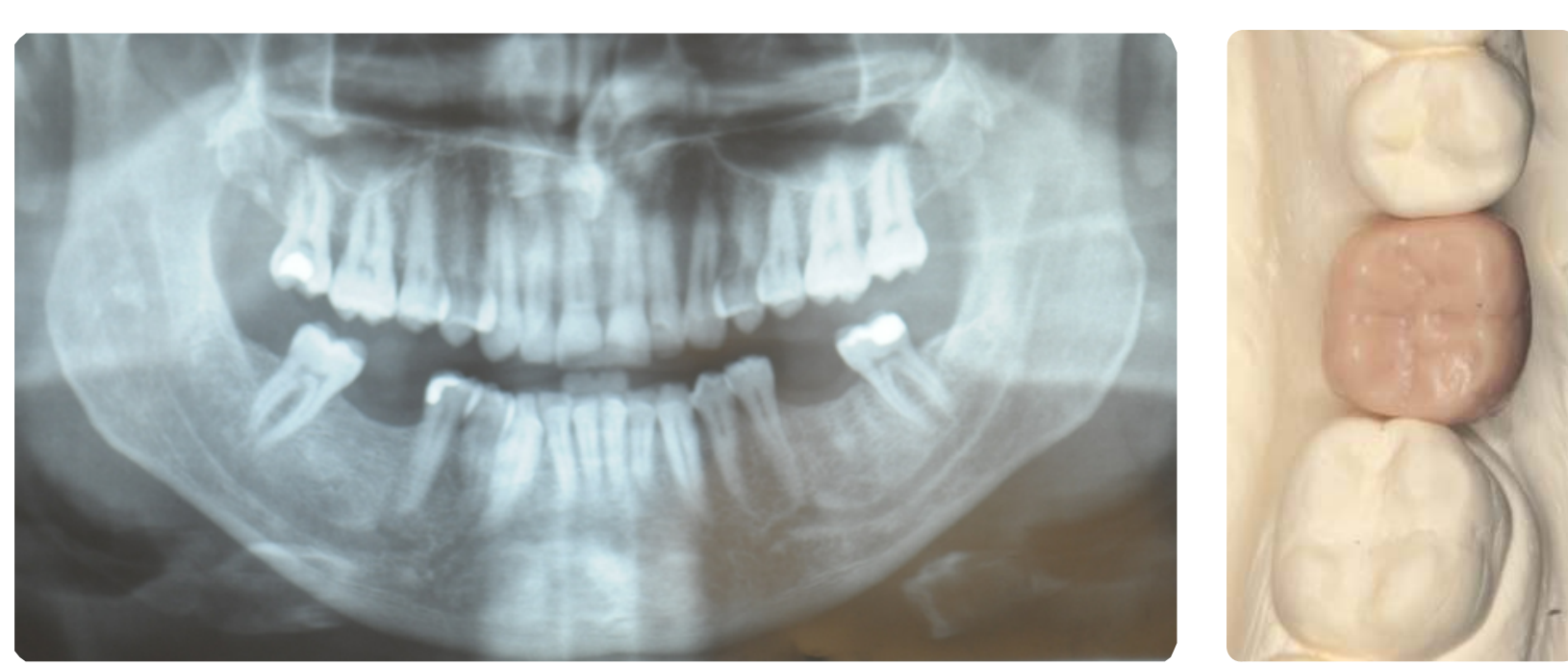

Figure 1-3: Preoperative evaluation and surgical planning

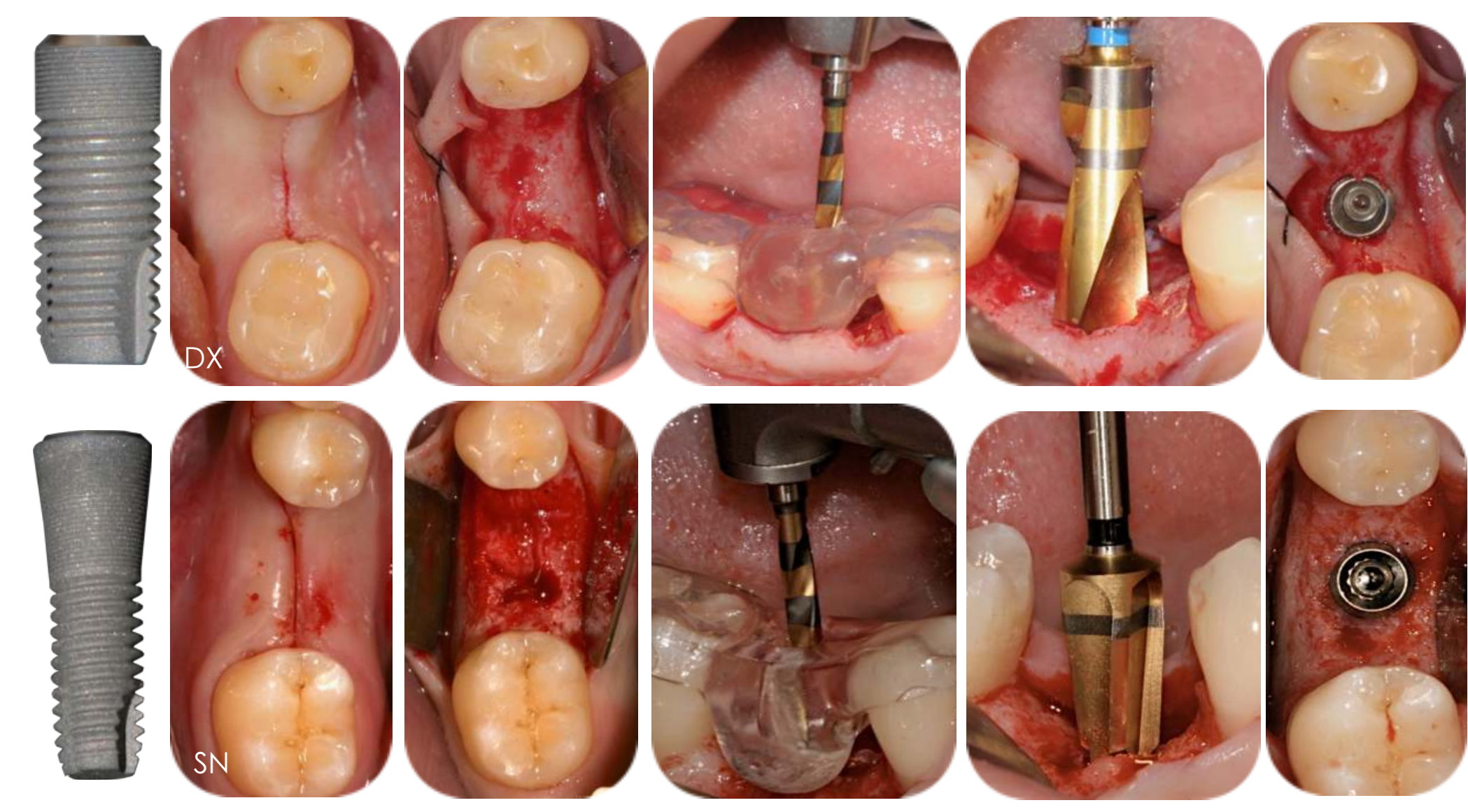

Figure 4-16: Surgical Phases

\section{Results}

All patients were evaluated at their last recall with a clinical evaluation and a periapical radiograph, standardized through the customization of a Rinn's film holder. No implant failed to osseointegrate or required to be removed. All patients maintained adequate plaque and bleeding on probing indexes during the follow-up period. The evaluation conducted on the periapical radiographs through an image processing and analysis software (Image $\mathrm{J} 囚$ ) revealed a marginal peri-implant bone loss ranged from 0 to $0.5 \mathrm{~mm}$ in $80 \%$ of cases and from 0.5 to 1 $\mathrm{mm}$ in $15 \%$. In a single implant (control group), a $1.9 \mathrm{~mm}$ vertical bone resorption was observed. Thus, the survival and success rates according to Albrektsson et al. criteria were $100 \%$ and $95 \%$, in the test and control group, respectively. No significant differences were observed between the two sites, with respect to $M B L$, peri-implant probing depth (PD) and bleeding on probing (BOP).
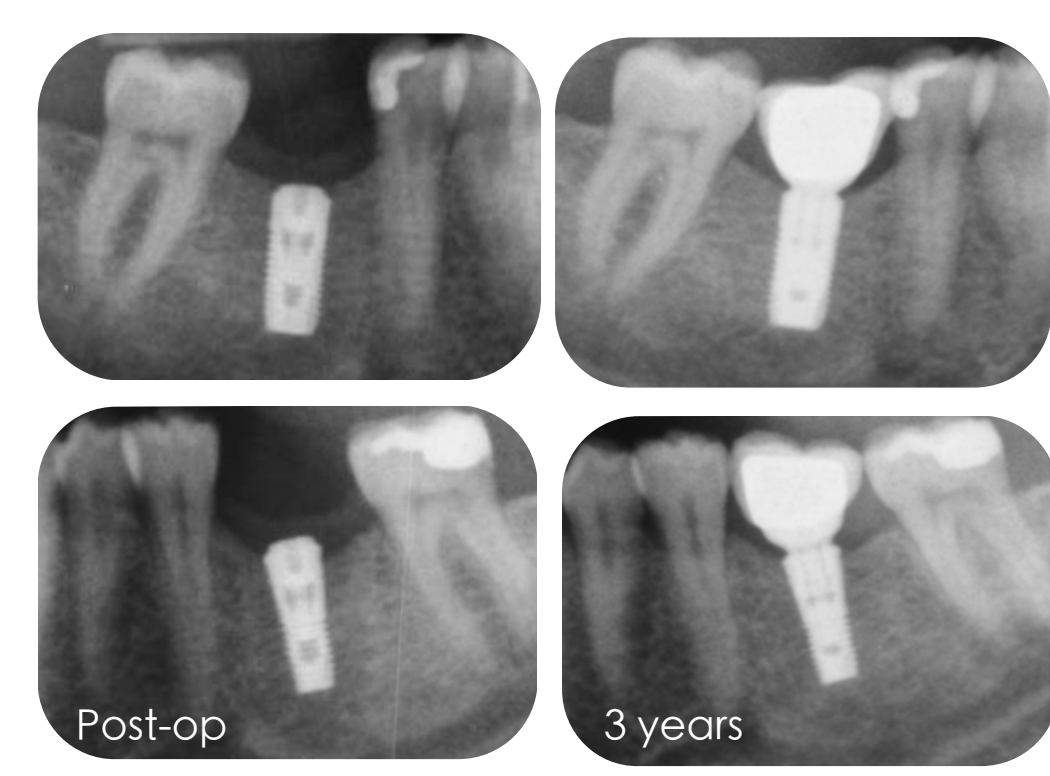

Figure 17-23: Radiographic follow-up

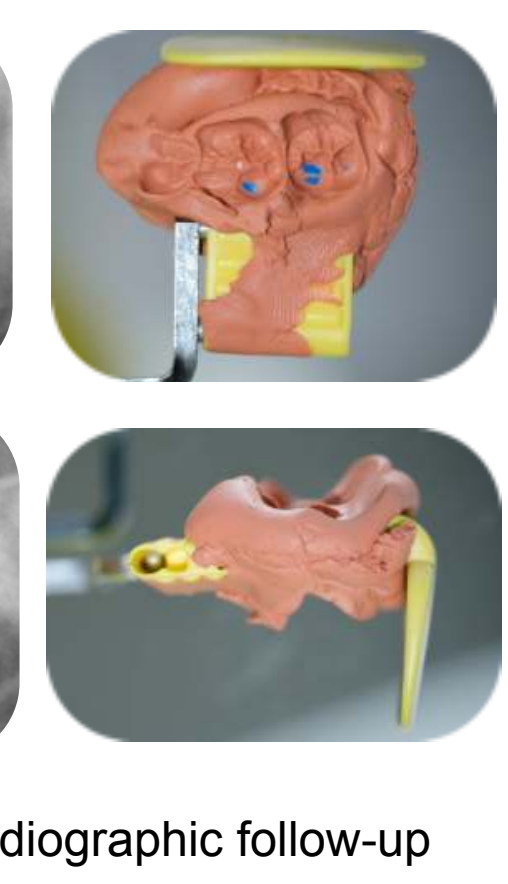

\section{Conclusions}

Despite the short follow-up period and the limited external validity of our results, this study suggest that large diameter implants with a straight or conical implant collar macrostructure are equally reliable in the rehabilitation of single tooth posterior edentulous spaces.

\section{References}

Hermann JS, Buser D, Schenk RK, Cochran DL. Crestal bone changes around titanium implants.
A histometric evaluation of unloadded non-submerged and submerged implants in the canine mandible.
Periodontol. 2000 Sep 71 (1) 1 1412-24. 2. Schnitman PA, Shulman LB. Recomm

3. Kim JJ, Lee DW, Kim CK, Park KH, Moon IS. Effect of conical configuration of fixture on the maintenance of
marginal bone level: preliminary results at 1 year of function. Clin Oral Implants Res. 2010 Apr 1;21 (4):439-44. 4. Quirynen, M. Naert I. \& van Steenberghe, D. (1992) Fixture design and overload influence mar- ginal bone loss
and fixture success in the Bràne- mark system. Clin Oral Implants Res. 3: 104-111. 5. Malevez, C.H., Hermans, M. \& Daelemans, P.H. (1996) Marginal bone levels at Bra nemark system implants
used for single tooth restoration. The influence of implant design and anatomical region. Clin Oral Implants Res.

6. Nordin, T., Jonsson, G., Nelvig, P. \& Rasmusson, L. (1998) The use of a conical fixture design for fixed partia
prostheses. A preliminary report. Clin Oral Implants Res. 9: 343-347. Misch, C.E. \& Bidez, M.W. (1999) A scientific rationale for dental implant design. In: Misch, C.E., ed.
Contemporary Implant Dentistry. 2nd edition, 329-343. Missouri: Mosby 8. Huang, H.L., Chang, C.H., Hsu, J.T., Fallagatter, A.M. \& Ko, C.C. (2007) Comparison of implant body designs
and threaded designs of dental im- plants: a 3-dimensional finite element analysis. The International Journal of
Ond the 